\title{
El coro de Suplicantes de Esquilo y la audiencia ateniense
}

The Chorus in Aeschylus' Suppliants and the Athenian audience

\author{
Julián Gallego \\ Universidad de Buenos Aires/Programa de Estudios sobre las Formas de Sociedad y las Configuraciones \\ Estatales de la Antigüedad-CONICET, Argentina julianalejandrogallego@gmail.com
}

http://orcid.org/0000-0002-3394-357X

\section{Resumen:}

El artículo analiza el coro de Suplicantes de Esquilo en el marco de los debates en torno al denominado “modelo Vernant” y postula la posibilidad de continuar aplicando dicho modelo sin perder de vista los planteos críticos. El examen parte del protagonismo del coro y su relación con los personajes y considera las posibles repercusiones que la performance pudo generar en la audiencia a partir de la figura de Pelasgo como la que opera sobre la implicación entre el coro y el público, ponderando los aspectos políticos que la tragedia pone de relieve, inherentes a las pautas institucionales de toda pólis griega, así como a ciertas características específicas de la democracia ateniense.

Palabras clave: Esquilo, Vernant, Danaides, Dánao, Pelasgo, Audiencia.

\section{Abstract:}

The article analyzes the chorus of Aeschylus' Suppliants in the context of the debates around the so-called "Vernant model", assuming the possibility of continuing to apply that model without loosing sight of critical issues. The study starts from the leading role of the chorus and its relations with characters and ponders the conceivable repercussions that performance could generate on the audience considering the figure of Pelasgus as the one that operates on the involvement between the chorus and the public, weighing the political aspects that tragedy highlights, inherent to the institutional patterns of every Greek polis as well as to some specific characteristics of Athenian democracy.

Keywords: Aeschylus, Vernant, Danaids, Danaus, Pelasgus, Audience.

Para los antiguos griegos la actuación coral era una parte medular de la vida social y cultural que permeaba los momentos más significativos de la existencia pública o privada, religiosa o secular, de la comunidad y las personas, desde los grandes festivales estatales hasta las bodas y los funerales. En todos estos planos, dice Swi $\mathrm{ft}(2010$, pp. 1-2, 35-42), el hecho de actuar en, o solo observar, este tipo de performance tenía un papel muy significativo porque representaba la inmersión en los valores de la comunidad y la participación en su vida ritual, política y cultual. Este contexto no puede ser olvidado, en la medida en que los espectadores en el teatro no veían en el coro trágico solo una convención propia del drama, sino una práctica muy familiar en su vida cotidiana.

A estas condiciones generales se suma, en virtud del corpus elegido, ${ }^{1}$ a peculiaridad de Suplicantes de Esquilo, posiblemente representada en 463 a.C. Solo por citar el más reciente estudio sobre la obra: "Unusually, though not uniquely (consider Eumenides), the chorus (the Danaids) have a highly active and indeed leading role in the drama"; a lo cual añade más adelante: "By far the most important dramatis persona in Supp. is the chorus of Danaids, who play a more prominent role than any other chorus in surviving Greek tragedy" (Sommerstein, 2019, pp. 10 y 34). Esta posición tiene como destacado antecedente el análisis de Garvie (2006, pp. xii-xiii, 106-110, 138-139), quien opina que se trata de un deliberado intento de integrar al coro en la acción de una tragedia y darle su propio carácter, un experimento realizado cuando aún no se había introducido el tercer actor. ${ }^{2}$ En las cinco décadas que median entre la primera edición del estudio de Garvie 
(1969) y el reciente libro de Sommerstein, los especialistas no han dejado de destacar este rol protagónico del coro de Danaides como marca singular de la obra. ${ }^{3}$

En este artículo proponemos un examen de esta performance coral en el contexto de los debates sobre la función del coro trágico desarrollados durante los últimos cincuenta años, a partir de la posición sentada por lo que se ha denominado "el modelo Vernant". Presentamos primero diferentes posturas adoptadas en torno a este modelo partiendo de las formulaciones originales que han organizado el campo disciplinar y postulamos la posibilidad de continuar aplicando el "modelo Vernant", releído a la luz de las críticas que se le han planteado. Abordamos luego la organización de la trama de Suplicantes en relación con el protagonismo del coro, con el fin de evaluar ciertos factores que juzgamos condicionantes de las características inherentes a los personajes y las posibles repercusiones que la performance pudo generar en la audiencia. En el examen de esta cuestión ponemos especial atención en la figura de Pelasgo como la que opera sobre la relación entre el coro y el público, ponderando los aspectos políticos que contiene la tragedia, en relación tanto con la pólis griega como con la democracia ateniense.

\title{
LA VOZ COLECTIVA DEL CORO: ROL DRAMÁTICO, AUDIENCIA Y COMUNIDAD CÍVICA
}

Uno de los análisis del papel y la función del coro en las representaciones trágicas que ha marcado las discusiones recientes ha sido la perspectiva planteada por Vernant:

\begin{abstract}
Le masque peut, entre autres choses, servir à souligner la distance, la différenciation entre les deux éléments qui occupent la scène tragique, éléments opposés mais en même temps étroitement solidaires. D'une part, le chœur, dans le principe, semble-t-il, non masqué, mais seulement déguisée, personnage collectif, incarné par un collège de citoyens ; d'autre part, le personnage tragique, joué par un acteur professionnel, et que son masque individualise par rapport au groupe anonyme du chœur. [...] Polarité donc, dans la technique tragique, entre deux éléments : le chœur, être collectif et anonyme, dont le rôle consiste à exprimer dans ses craintes, ses espoirs et ses jugements, les sentiments des spectateurs qui composent la communauté civique ; le personnage individualisé, dont l'action forme le centre du drame et qui a la figure d'un héros d'un autre âge, toujours plus ou moins étranger à la condition ordinaire du citoyen. A ce dédoublement du chœur et du héros tragiques correspond, dans la langue même de la tragédie, une dualité : d'une part, le lyrisme choral ; d'autre part, chez les protagonistes du drame, une forme dialoguée dont la métrique est plus voisine de la prose. Les personnages héroïques rapprochés par la langue de l'homme ordinaire, ne sont pas seulement rendus présents sur la scène aux yeux de tous les spectateurs, mais à travers les discussions qui les opposent aux choristes ou les uns aux autres, ils deviennent l'objet d'un débat ; ils sont en quelque sorte mis en question devant le public. De son côté, le chœur, dans les parties chantées, exalte moins les vertus exemplaires du héros, comme dans la tradition lyrique de Simonide ou Pindare, qu'il ne s'inquiète et ne s'interroge à son sujet. Dans le cadre nouveau du jeu tragique, le héros a donc cessé d'être un modèle ; est devenu, pour lui-même et pour les autres, un problème (Vernant y Vidal-Naquet, 1972, pp. 13-14; cf. p. 27; Vernant y Vidal-Naquet, 1986, pp. 21-24).
\end{abstract}

De todas estas cuestiones planteadas por Vernant hace cinco décadas, el punto más controversial radica en la asociación entre el coro y los espectadores que componen la comunidad cívica, puesto que da por sentado que, al expresar los sentimientos de esta última mediante temores, esperanzas y juicios, el coro sería el procedimiento a través del cual los autores trágicos harían lugar a una representación de la ciudadanía ateniense sobre la propia escena teatral. Si el coro cumplía esta función, se podría sugerir entonces que habría en la configuración del discurso trágico un aspecto metateatral llamado a formar parte de la propia puesta en escena, desde la concepción misma de la tragedia según la conocemos, siendo dicho aspecto parte de la estructura inherente a las obras.

Los señalamientos del propio Vernant llevan a introducir la siguiente interrogación. Si el coro con sus expresiones cumple el papel de dar un lugar a la comunidad cívica, claramente la lírica coral no es el modo con el cual los integrantes de esta colectividad se expresan a diario (Silk, 1998b, p. 16). El héroe como figura individualizada, ajena a la condición ordinaria de los ciudadanos que integran la comunidad cívica, habla una lengua que parece, en cambio, ponerlo en un registro cercano al común del público, a partir de formas dialogadas con una métrica próxima a la prosa. Si se considera, pues, este otro aspecto de las obras trágicas, 
el personaje heroico del pasado, convertido en problema que se debate y cuestiona en escena, aparece con un lenguaje que lo coloca próximo a los espectadores de los que el coro expresaría sus sentimientos. VidalNaquet amplía la interpretación esbozada en un prefacio a una edición de Sófocles:

Le chœur exprime donc à sa façon, face au héros atteint de démesure, la vérité collective, la vérité moyenne, la vérité de la cité. [...] Mieux, si le chœur est l'organe d'expression collective et civique, il est tout à fait exceptionnel qu'il soit composé de ceux qui étaient des citoyens moyens, c'est-à-dire les adultes mâles en âge de combattre (Vernant y Vidal-Naquet, 1986, pp. 158-159).

En las reflexiones que siguen a estos pasajes, Vidal-Naquet aclara que esta "verdad" colectiva, común, de la ciudad no se confunde con las formas concretas de cada coro en el conjunto de las tragedias completas disponibles: coros de mujeres, abarcando también a esclavas, de ancianos, de extranjeros, incluso de divinidades, muestran que no es en la identidad adquirida por cada coro donde habría que buscar esa verdad que, en su estructura, el coro viene a expresar. Las propuestas de Vernant y Vidal-Naquet forman parte de una línea de pensamiento que se puede seguir en un conjunto de análisis que pone de relieve el carácter específico del papel del coro, así como el problema de la relación entre lo que ocurre en la representación y la posición de la audiencia.

El público reunido en el teatro y compuesto en su mayoría por ciudadanos atenienses supone una entidad colectiva que, como audiencia, se relaciona en el espacio escénico con la arena de la acción dramática. Este aspecto comunitario se realiza específicamente en la actuación del coro como representativo del cuerpo cívico (Longo, 1990). Coro y audiencia compartirían la experiencia de ser un grupo ante los individuos, personajes o magistrados, según una forma de articulación que se ajusta a los principios ideológicos de la democracia ateniense en la que la soberanía colectiva supeditaba a los individuos: como intermediario espacial, temporal y comunicativo respecto de los actores, el coro representaría a los espectadores dentro de la obra (Mastronarde, 2010, pp. 89-98). ${ }^{4}$

Frente a este conjunto de posturas que, aun con discrepancias, han tendido a destacar la relación que de una forma u otra ligaba a los coros trágicos (o al menos a una parte de ellos) con los espectadores, básicamente identificados con los ciudadanos atenienses, se ha desarrollado otro modo de indagar el rol del coro atendiendo al estatus generalmente marginal de la identidad conferida al conjunto de sus integrantes: mujeres, esclavas, extranjeros/as, etc. Este tipo de análisis ya no sigue los parámetros de quienes asumen un papel mediador del coro sino los de la identidad coral en el marco interno de la obra.

Gould (1996, pp. 220-221, 233) aborda el rol del coro criticando lo que bautiza como "modelo Vernant" y subrayando la otredad respecto de la comunidad ciudadana, puesto que la mayoría de los coros desempeña un papel marginal, no representativo del cuerpo cívico, condición desde la cual reflexiona acerca de los eventos trágicos. Esta posición se define en relación con, por un lado, la situación de la Atenas democrática cuyo núcleo político era la comunidad de ciudadanos hoplitas, y, por el otro, la sociedad ficcional de las tragedias por lo general organizada en torno a héroes aristocráticos. Pero esto no supone una pauta universal, sino que cada coro es un grupo particular cuyo discurso no adquiere ni un sentido de verdad ni una autoridad primordial. $^{5}$

Goldhill (1996, pp. 251-253) pondera las críticas de Gould y su reconocimiento del lugar desde el cual habla el coro y la variedad en la construcción y el funcionamiento del mismo. Los reparos del autor radican sobre todo en la correlación que instaura Gould entre posición social y autoridad, puesto que la otredad y la marginalidad social no implican una voz carente de autoridad. Según el autor, la voz colectiva del coro que apela al mito para movilizar la sabiduría y la memoria social heredadas es un discurso autorizado y constituye un punto de articulación con el público para el cual puede funcionar como autoridad colectiva. ${ }^{6}$ Si bien acepta la formulación de Gould sobre el "modelo Vernant", Goldhill (1996, pp. 244-245) ha profundizado más que ninguno el análisis de la postura de Vernant, pero no solo a partir del vínculo que se puede trazar 
entre los sentimientos del público y las expresiones del coro, sino también de la perspectiva de Vernant en cuanto a la "conciencia trágica" de los espectadores: ${ }^{7}$

For Vernant, the spectator has a clear view of ambiguity, then, and it is through this recognition that he 'acquires a tragic consciousness' (conscience tragique), that is, the anagnorisis integral to tragedy and the tragic. The chorus as collective thus mirrors and directs the audience in its role as collective spectator, but it is only the audience that achieves 'tragic consciousness'. There are already, then, fundamental differences that ground the analogy between chorus and audience, the ways in which the chorus can 'represent the audience'. What needs further consideration, however, is the idealization that allows the audience a clear vision of ambiguity (p. 245).

El conjunto de las interpretaciones reseñadas constituye un marco apropiado a partir del cual encuadrar un examen del coro de Suplicantes de Esquilo, que constituye uno de los cinco coros femeninos entre sus siete tragedias conservadas completas. A la luz de las reflexiones de los especialistas y de lo que escenifican las tragedias de Esquilo, ciertamente, es difícil afirmar sin más que el coro de Suplicantes es representativo de la comunidad cívica que constituía la audiencia. ${ }^{8}$ Pero no perdamos de vista que Vernant no hacía referencia a un carácter representativo per se del coro respecto del cuerpo político, sino a la posible expresión de sentimientos de este cuerpo como espectador en el teatro, por medio de los temores, las esperanzas y los juicios del coro. Este matiz, evidente en las propias palabras del autor, no ha sido ponderado adecuadamente por las críticas planteadas a su postura, o incluso por quienes la han adoptado. ${ }^{9}$

A partir de las posiciones revisadas, la lectura que se propone de Suplicantes busca poner a prueba las conjeturas de Vernant, indagando tanto el papel dramático del coro de Danaides en el contexto mítico de la ciudad de Argos de Pelasgo como los posibles sentimientos del público que el coro pudo haber evocado con sus temores, esperanzas y juicios. En este sentido, la postura aquí adoptada se encuentra próxima a la adaptación del modelo de Vernant propuesta por Budelmann (2000, pp. 195-272) para resolver sus imprecisiones (con las debidas reservas del caso, porque el autor plantea su perspectiva con el fin de analizar las tragedias de Sófocles). En tanto que grupo, el coro involucra a la audiencia que también forma un grupo. El coro es la única perspectiva grupal que se ofrece a la audiencia en el teatro, lo cual puede ser una vía de implicación. Esto se puede operar mediante una serie de trasposiciones: del coro al grupo más amplio de la pólis en general y del pueblo fuera de la escena, y de estos al involucramiento de los espectadores, allende la orkhéstra, y por consiguiente a los atenienses:

By avoiding the glosses 'civic community' for the chorus and 'heroes from another age' for the individual characters, and instead discussing various ways in which various spectators can look at the action, he [Vernant] presents a generally persuasive model of audience involvement (p. 198).

\section{EL PROTAGONISMO DEL CORO Y LA RESIGNIFICACIÓN DE LOS ROLES ESCÉNICOS}

La posibilidad de indagar las posibles formas de interpelación a la audiencia por parte del coro de Suplicantes, según la idea de que podría estar expresando sus sentimientos, implica al menos dos niveles interpretativos: las marcas discursivas por medio de las cuales se puede detectar los enunciados empleados en las situaciones en que el coro convocaría al público y la información que durante el desarrollo de la obra se aporta a la audiencia. El primer aspecto supone que la "expresión" de los sentimientos del público no es una función permanente del coro y que hay una articulación entre su rol dramático dentro de la trama y los mensajes que desde esa posición envía a los espectadores. El segundo aspecto implica que toda representación, aun si apela al bagaje cultural del auditorio, no por eso da por sentado que tácitamente invoca una versión del mito sin incluir toda la información pertinente durante el propio desarrollo de la narración. ${ }^{10}$

Partamos de la constatación de que el papel central del coro en Suplicantes es una experimentación poco habitual que no deja inalterada la posible conjunción entre coro, grupo amplio y audiencia, a la vez que también altera los roles de los actores personajes. Fernández Deagustini (2015, pp. 130-185) lo indica con 
claridad: el coro de Suplicantes es un “coro-carácter" con una función protagónica; es respecto de la actuación del coro que se definen los roles de Dánao como coprotagonista y de Pelasgo como antagonista. Esto obedece no solo a la actuación concreta de este personaje colectivo, sino también al lugar que ocupa en la economía de la obra: prácticamente, no hay ningún momento en que, cuando el coro no interviene, no se esté haciendo referencia de una manera u otra a las Danaides. Ante esta singularidad de Suplicantes, en lo que atañe a los sentimientos del público que el coro pudo haber evocado o expresado la consecuencia metodológica es que, a mi entender, no se puede separar taxativamente las intervenciones puntuales del coro de lo que los personajes señalan en relación con las Danaides; la vinculación con los espectadores, entonces, se debe contemplar a la luz de toda la información que se ofrece sobre este personaje en torno del cual se vertebra la trama trágica.

En el apartado previo citamos la postura de Budelmann sobre las posibles formas de involucramiento del coro con un grupo amplio y, a partir de esta mediación, con la audiencia. El coro como multitud es el único elemento grupal que el público encuentra en la performance concreta, y de allí la oportunidad de identificarse, aun cuando los rasgos conferidos a los coros no sean los de la comunidad cívica. Pero esta condición general no es suficiente para comprender el modo en que los espectadores pudieron elaborar algún tipo de implicación con el coro de Suplicantes. Al introducirnos en su trama específica, cabe preguntarse: ¿en qué medida este coro protagonista puede asumir la función de expresar los sentimientos del público? ¿Cómo estas mujeres, extranjeras, incluso de piel negra para agravar la extrañeza, pudieron mediante la performance coral generar el compromiso de una audiencia ampliamente adulta, masculina y ciudadana?

Cuando Vernant proponía su interpretación del coro se refería fundamentalmente a uno que no tiene un rol protagónico, y en algún sentido se podría cuestionar si no es una operación forzada aplicar su visión al estudio del coro de Suplicantes. Ciertamente, a diferencia de otros coros, formados por cautivas, o mujeres, o ancianos o varones armados, que no se distinguen entre sí y sobre cuyas vidas no se tiene antecedente alguno, las Danaides forman parte de los mitos recreados en escena. ${ }^{11}$ Rebasando el carácter anónimo del grupo de 12 o 15 ciudadanos que componen el coro (cf. Sansone, 2016), las máscaras identifican a las Danaides, lo mismo que sucede con la máscara individual que identifica al héroe; no tienen las máscaras de cualquier mujer extranjera, común, desconocida, sino que el coro representa a las hijas de Dánao, doncellas con nombres propios cuya historia se conoce. Al igual que los héroes individualizados por sus máscaras, también las Danaides se individualizan, pero grupalmente, dicho mediante un oxímoron. Por consiguiente, se podría pensar que hay en toda esta disquisición un punto de desautorización de la tesis de Vernant, ya que no se comprobaría la separación taxativa de roles entre el personaje individual que porta la máscara del héroe y el coro, y, precisamente por este motivo, tal vez las únicas distinciones ciertas serían aquellas entre un individuo y un grupo y entre las formas propias de las partes dialogadas y las del lirismo coral. Pero no nos anticipemos a extraer conclusiones apresuradas y, por ahora, solo advirtamos esta situación.

Por otra parte, es evidente que los temores, esperanzas y juicios de un coro engloban una amplia gama de intervenciones; la expresión de los sentimientos planteada por Vernant no supone una inmediata identificación entre los espectadores y el coro por el solo hecho del carácter grupal de ambos, a la vez que los sentimientos no tienen que ser necesariamente identitarios, sino que pueden ser precisamente lo contrario, refractarios: el involucramiento puede implicar tanto la aceptación como la censura, con todo el arco de matices que median entre una actitud y otra. En cuanto a Suplicantes, nos parece que la tragedia construye una serie de mediaciones que permite transitar desde aspectos o comportamientos que pueden haber generado reacciones refractarias, ${ }^{12}$ a otros que pueden haber producido sentimientos identitarios. ${ }^{13}$ Con los debidos recaudos, en tanto que el coro se presenta de entrada en la escena teatral implorando asilo, un mecanismo implícito, aunque ambiguo, es la empatía que dicha súplica es capaz de provocar, hecho que depende de una determinada configuración discursiva a través de la cual la condición de las Danaides puede producir en el público algún modo de implicación.

Así pues, el protagonismo de las Danaides constituye el operador que organiza en torno suyo los papeles relativos de los demás personajes en la configuración del drama. En este marco, el primer punto que se debe 
considerar es el rol de Dánao con respecto a las Danaides. Aquí es necesario establecer una distinción entre la función como padre en relación con sus hijas, es decir, la manera en que se recrea el mito imprimiéndole, y la función estructural como personaje en relación con el coro, es decir, la forma en que se organiza la trama según los roles que discursivamente se asignan al actor (Dánao) y a los coreutas (las Danaides). Existen marcas de la función de Dánao como padre que muestran la dirección que ejerce sobre sus hijas, ${ }^{14}$ cabe decir la patria potestad. Esto es esperable en sociedades patriarcales, salvo que se presente una ruptura de los mandatos, lo cual no es el caso. De todos modos, hay una elección por parte de Esquilo de reafirmar en diferentes pasajes la configuración del vínculo paterno-filial al representar a Dánao no solo ejerciendo su función de padre sino también como aquel que planifica el conjunto de la estrategia, dirige la operación, incluyendo la huida y en especial la navegación (que ya es toda una metáfora del proceso en su conjunto), ${ }^{15}$ y recomienda a cada paso las formas adecuadas de comportamiento de las Danaides. Pero este rol no se debe confundir con el liderazgo, por así decirlo, que técnicamente ejerce el corifeo durante la puesta en escena, y menos aún con el papel del corego, que en general no participa de la representación: Dánao dirige el coro debido a los roles respectivos de padre e hijas, no en términos de la estructura de funcionamiento de la tragedia. ${ }^{16}$

En el plano de la construcción de la trama tal vez se pueda decir que forman un único personaje, o personajes complementarios (Fernández Deagustini, 2015, pp. 136-154). Como hijas de Dánao, las Danaides no hacen nada que no esté concertado con su padre, según su designio y sus deseos (Winnington-Ingram, 1983, p. 62), lo cual incluye el plan global de buscar asilo en Argos para evitar las bodas con los Egiptíadas y las recomendaciones que el padre va dando a sus hijas una vez llegados a tierra argiva. ${ }^{17}$ Dánao es quien guía a las Danaides en la consecución del objetivo; en este sentido, y como su propio nombre lo indica, las hijas son parte de la identidad del padre, no a la inversa. Pero, en la organización formal de la trama y en el desarrollo narrativo de la historia, Esquilo le confiere al coro una posición protagónica propia de un personaje con respecto al cual, en términos formales, Dánao deviene entonces un coprotagonista.

\section{Entre el coro y la audiencia: Pelasgo como focalizador}

En tanto que el coro organiza el reparto de roles de los personajes individuales en torno suyo y coloca a Dánao en la posición de coprotagonista, correlativamente sitúa a Pelasgo como antagonista. En este punto, la singularidad de Suplicantes radica en poner en escena un agón no entre dos personajes heroicos, que se distinguen del resto, sino entre un héroe individual y el coro como personaje colectivo con su propia identidad. En efecto, lo habitual en el corpus trágico conservado es el agón entre dos personajes individuales que en lo formal bien podría evocar el intercambio entre oradores, por supuesto, sin perder de vista las diferencias entre la trama trágica y la retórica, ya que no se trata de establecer una analogía inmediata entre lo que ocurre en la escena teatral y lo que el público trae como experiencia propia sobre las justas oratorias (cf. Duchemin, 1968). Pero en Suplicantes el intercambio es entre Pelasgo y las Danaides, y tras este agón el propio Pelasgo convoca de inmediato al pueblo para que se torne favorable a las súplicas a partir de un intercambio basado en la persuasión. Por ende, se puede pensar que hay un paralelismo entre el agón que se muestra en escena entre el héroe y el coro y el que se convoca como imagen entre los espectadores al aludir al intercambio que ocurre fuera de escena en la asamblea entre Pelasgo y el pueblo, cuando se toma la decisión política de dar asilo a las suplicantes. Si en otras tragedias una formación coral no tiene una voz protagónica y puede aparecer limitándose a comentar una situación, en el caso de Suplicantes el papel principal del coro como conjunto y la toma de la palabra de manera colectiva parecen ser una manera de mostrar qué puede significar que un grupo tenga voz propia y cómo esa multitud opera persuasivamente ante un individuo.

Las presentaciones de las Danaides y Pelasgo no están exentas de ambigüedades y formulaciones contradictorias: el coro está constituido por mujeres, extranjeras, negras; Pelasgo al aproximarse con su séquito no se distingue de los demás. Las Danaides narran en sus cantos iniciales su relación con la tierra argiva 
en virtud del parentesco con Zeus e Ío, aunque su modo de hablar sea bárbaro (1-175). Sin embargo, no es esperable todavía una caída de las apariencias en estas escenas, cuando sus alusiones resultan enigmáticas para el público y solo parece quedar en claro que huyen de Egipto a causa de unas bodas que consideran impías $(\gamma \dot{\alpha} \mu \circ v . . . \dot{\alpha} \sigma \varepsilon \beta \tilde{\eta})$ y suplican a los dioses de la ciudad para obtener asilo y protección frente a sus pretendientes. El coro emplea un conjunto de imágenes que sintetiza los diversos planos de articulación entre la pólis,

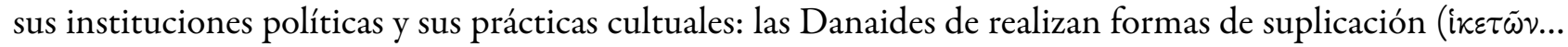
$\kappa \lambda \dot{\alpha} \delta \circ / \sigma \iota v)$ que muestran apego a los rituales griegos $(1-2,21-22)$; no hay un decreto de la ciudad ( $\psi \dot{\eta} \phi \omega$ $\pi \dot{\partial} \lambda \varepsilon \omega \varsigma)$ que las haya expulsado por cometer un crimen de sangre ( $\alpha i \mu \alpha \tau \iota \delta \eta \mu \eta \lambda \alpha \sigma i \alpha \nu)$ (6-7; cf. 196); huyen del

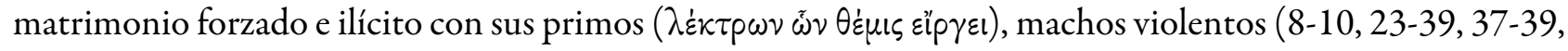
141-143, 151-153; cf. 226-229, 332, 487); solicitan la protección ( $\kappa \eta \delta \varepsilon \mu \dot{\omega} \nu)$ de los argivos (53-54, 73-75); y

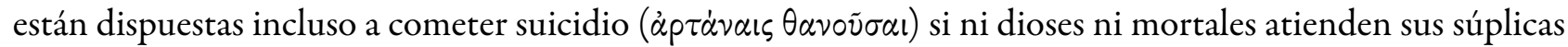
(160-161; cf. 115-116, 465). La escena posterior con Dánao amplía la información precedente, además de enfatizar el rol paterno y la percepción que de unas doncellas extranjeras debe obtener el ejército argivo que se aproxima, reafirmando sobre la escena la autoridad paterna en el vínculo con sus hijas y el carácter subalterno de su protagonismo dramático (176-233).

La distancia, la otredad, es lo que Pelasgo destaca de entrada al producirse su llegada al lugar en que las Danaides imploran a los dioses; ni por la vestimenta, fastuosa, bárbara y abigarrada, ni por la forma de presentarse en el lugar, sin heraldo, ni próxenos, ni guía, las suplicantes parecen argivas o griegas, excepto por la forma en que observan los rituales de suplicación (234-245). Para las jóvenes tampoco está claro quién es el que les habla: ¿un hombre común, un orador con su vara sagrada, el gobernante de la ciudad? (246-248). Junto con la presentación, esta escena muestra un conjunto de rasgos que parece desdibujar una posible identificación inicial de la audiencia con el coro, salvo en su carácter grupal. La presentación de Pelasgo, en cambio, con las ambigüedades que su porte genera a los ojos del coro, parece abonar la idea de una interpelación identitaria a los espectadores, a partir de lo que su figura muestra en términos de semejanza con cualquier otra cuya identidad básica es la de un argivo que puede adquirir el rol de orador o gobernante, anticipando la condición igualitaria que la toma de la decisión pondrá de relieve. El público asiste en este primer intercambio a una clara demarcación de fronteras que solo va a lograr deshacerse a partir de lo que depare la continuidad del agón entre Pelasgo y las Danaides.

Esto ocurre en virtud de un doble movimiento: por un lado, la información que el coro ofrece sobre sí mismo y la aceptación y el convencimiento que van ganando el ánimo de Pelasgo sobre el origen argivo de las Danaides; por el otro, los límites en el ejercicio del poder que Pelasgo se autoimpone según sus propias palabras. Pero antes de que se deshagan las apariencias, Esquilo la lleva hasta un punto extremo, contrario a lo que finalmente saldrá a la luz. Pelasgo afirma que es el jefe del país ( $\left.\gamma \tilde{\eta} \varsigma \dot{\alpha} p \chi \eta \gamma^{\prime} \tau \eta \eta \varsigma\right)$, a cuyos habitantes les da su nombre por ser el rey ( $\alpha \nu \alpha \kappa \tau \circ \varsigma)$, y que domina un territorio ( $\pi \tilde{\alpha} \sigma \alpha \nu \alpha \tilde{\alpha} \alpha \nu \ldots \kappa p \alpha \tau \tilde{\omega})$ cuyo límite es el

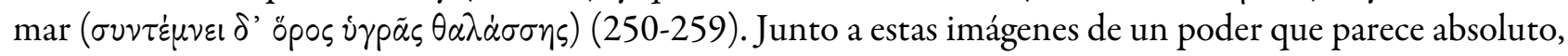
y ante la afirmación de las Danaides de pertenecer a la estirpe argiva, Pelasgo pone en palabras la imagen que él mismo se hace de ellas hasta ese momento, y posiblemente también la audiencia: extranjeras, parecidas a mujeres libias, en modo alguno son como las lugareñas, sino semejantes a grabados chipriotas de artesanos feminizados, o a las mujeres nómadas de la tierra vecina a Etiopía que cabalgan sobre camellos (277-286); y agrega: "También os hubiera confundido, si armadas con arcos estuvierais, como esas Amazonas, sin maridos

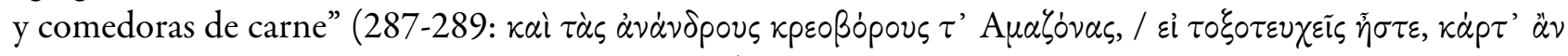
$\eta_{\eta} \kappa \alpha \sigma \alpha /$ i $\mu \tilde{\alpha} \varsigma ;$ cf. Sommerstein, 2019, pp. 172-173).

Estas dos descripciones de Pelasgo señalan la máxima separación entre las Danaides y él y entre el coro y el público, reafirmando la extrañeza que generan las suplicantes para la mirada griega. No parece haber identificación de los espectadores con las doncellas y tampoco un involucramiento con su causa en este momento, cuando apenas han empezado a exponer su situación. Desde esta máxima distancia, Esquilo hará converger las posiciones hasta llegar a una fórmula, también en boca de Pelasgo, que es un oxímoron 
(Papadopoulou, 2011, p.70; cf. Fernández Deagustini, 2015, pp. 164-165, 255) y que establece la síntesis con la que las extrañas Danaides serán aceptadas como huéspedes, por su origen argivo: “ $¡ O j a l a ́$ que este asunto de los ciudadanos-extranjeros no sea luctuoso, ni de lo inesperado e imprevisible se derive una guerra para la

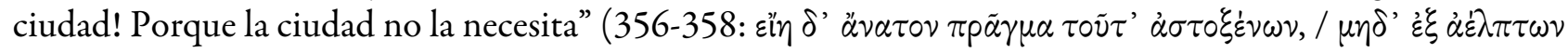

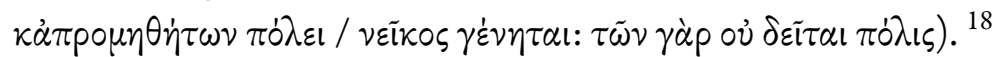

Hasta este momento de la narración, Pelasgo se presenta con unas características que no son diferentes a las de otros héroes que ejercen el poder y hablan de sí mismos en términos de dominio personal. La distancia parece también establecerse entre el héroe de antaño y la audiencia ateniense, siguiendo de entrada aparentemente las pautas que la tragedia suele asignar al personaje heroico (cf. Lanza, 1977; Miralles, 1992). Así, no será solo entre los ciudadanos argivos y las doncellas extranjeras que la convergencia se produzca, sino que al mismo tiempo Esquilo hará a Pelasgo desandar el camino típico del héroe trágico, más o menos emparentado con una figura tiránica, para mostrarlo en escena como un líder político cuyos métodos no resultarán distantes para la audiencia.

En efecto, lo que se esperaría de una figura como Pelasgo, una vez que ha señalado los límites de su territorio, es una capacidad política acorde con esa descripción; no obstante, él jamás deja de responder a los mandatos derivados de un liderazgo que no lo muestra por encima de nadie, reafirmando la libertad para el uso de la

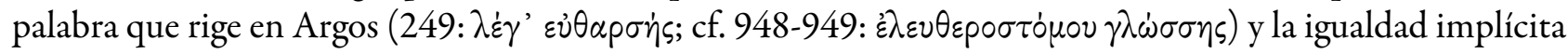
en el hecho de que pueda ser confundido con un ciudadano cualquiera. Bajo estas premisas, Pelasgo pone en claro que el pedido de las Danaides no se dirige a él o a su casa particular, sino al conjunto de la ciudad ( $\tau \dot{o}$ koเvòv... $\pi \dot{\partial} \lambda ı \zeta)$, que es la que tiene que resolver la situación, convocando para ello a todos los ciudadanos

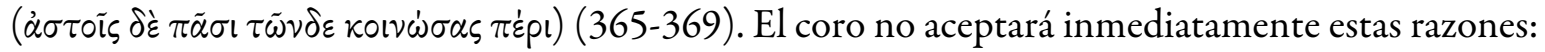

Tú eres la ciudad, tú eres el pueblo. Tú eres un jefe inviolable, gobiernas el altar, hogar de este país, con los únicos votos de tu gesto, y, sentado en tu trono, sin más cetro que el tuyo, resuelves cualquier cosa necesaria. Guárdate de esa mancha.

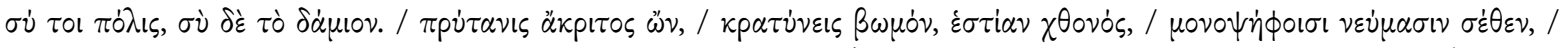

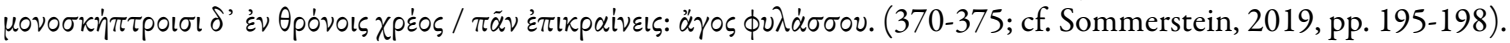

Esta insistencia de las Danaides para que Pelasgo decida por sí solo y ejerza un poder absoluto se puede considerar como un factor más de distanciamiento respecto no solo de las normas de los argivos sino también de la posición de la audiencia, conocedora de las prácticas y mecanismos de regulación que en la Atenas democrática procuraban acotar los poderes de individuos que por el poder personal acumulado pudieran asemejarse a tiranos. ${ }^{19}$ Por supuesto, esto no niega el papel del líder que la tragedia parece invocar; pero el expediente de convocar al pueblo que Pelasgo resalta es el que los espectadores esperarían ante una situación que implica a la comunidad en su conjunto, ${ }^{20}$ de acuerdo con las pautas de la suplicación y el otorgamiento de asilo, que en Atenas solía decidir la asamblea (Naiden, 2006, pp. 173-195), máxime cuando la posibilidad que se anticipa es la de una invasión y una guerra. Sobre esta base Pelasgo replica a las Danaides:

No es fácil de juzgar este pleito. No me elijas por juez. Y además te lo dije ya antes: no podría hacer eso a la espalda del pueblo, ni siquiera teniendo el poder, no sea que algún día diga la muchedumbre, si por ventura algo no sucediera bien: 'Por honrar a extranjeras, causaste la perdición de la ciudad'.

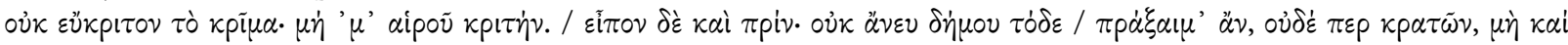

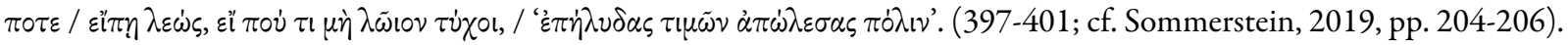

En la medida en que esto se confirme con la convocatoria a la asamblea, cobra relieve en este proceso dramático la afinidad entre esta figura y los espectadores, que Fernández Deagustini (2018) establece en estos términos: "Pelasgo, por tratarse del único personaje griego del drama, es el más próximo a la audiencia y, como consecuencia, permite pensar en la coincidencia entre ambos en cuanto a su actitud ante los hechos y sus juicios de valor" (p. 28). En su carácter de líder político de Argos, Pelasgo muestra sobre la escena que el público no encontrará en él a un personaje atravesado por la falta, empezando por el hecho de apartarse de los rasgos tiránicos habituales de otros héroes trágicos; para reforzar la coincidencia con los espectadores 
mayoritariamente atenienses, las cuestiones cardinales para la ciudad se deciden democráticamente en asamblea. Si bien es cierto que, como dice también Fernández Deagustini (2018), "Suplicantes propone una perspectiva diferente de los acontecimientos míticos, al disociar la figura protagónica (Danaides) de la figura heroica (Pelasgo), al tiempo que promueve la afinidad y solidaridad del público con este último, distanciándolo del personaje colectivo del coro" (p. 28), nos parece que en el desarrollo de la trama la actitud de Pelasgo ante el dilema que se le presenta y la decisión que propugna de aceptar a las Danaides como residentes legales, buscando persuadir al pueblo para lograr este objetivo, terminará produciendo una transferencia hacia el coro de esa afinidad y solidaridad entre la audiencia y este personaje heroico.

En efecto, Pelasgo enseña a las astóxenoi los valores y normas de la ciudad de Argos (que remeda a Atenas; Pattoni, 2017), y, a la vez que rechaza asumir el poder absoluto que el coro quiere endilgarle, va dando cuenta sobre la escena de su propio proceso de involucramiento con la situación de las suplicantes. La figura de Pelasgo en la primera parte de la obra se asienta en la promesa de mesura ante las circunstancias a partir de diversas premisas: respeto por los dioses, cuyos mandatos deben acatarse por sobre los de los mortales; rechazo de la tiranía y convocatoria a todo el pueblo para que decida por sí mismo colectivamente y se haga responsable; enfrentamiento a quienes no usen la persuasión para lograr su cometido y pretendan imponer sus intereses por la fuerza. Sobre la base de estas nociones, Pelasgo se coloca al frente de Argos como líder político que aglutina a la ciudad incluyendo la diversidad dentro de la unidad, una pólis que es capaz de hacer un lugar a las diferencias: mujeres, extranjeras, incluso bárbaras, de piel negra, que muestran comprensión acabada de las prácticas griegas respecto de los dioses y que terminan siendo huéspedes aceptadas en virtud de un origen cívico compartido.

Pelasgo opera como mediación política para que lo que las Danaides presentan en su carácter de extranjeras, cercanas incluso al bárbaro, se subordine a los aspectos que la unen al orden cívico. En cierto sentido, actúa como "focalizador", adaptando la noción aplicada por Griffith (1982, pp. 72-74; cf. Budelmann, 2000, pp. 197-201), en el sentido de que, en virtud de su cambio de punto de vista respecto del que inicialmente él mismo tenía, las Danaides devienen un grupo próximo, objeto de identificación y ya no de extrañeza, tanto para la mirada del grupo amplio de los argivos que lo acompaña como del conjunto de ciudadanos que se reúne en asamblea fuera de escena, y, en definitiva, del público presente en el teatro. Pelasgo como focalizador dramático opera sobre la escena como un elemento de transición e ilación entre tres conjuntos: el coro, el grupo amplio y la audiencia. Al tomar una posición e implicarse con la situación de las Danaides, Pelasgo está declarando a los espectadores que ese coro, evolucionando con sus danzas y sus cantos en la orkhéstra, entre el escenario y el graderío, y siguiendo, no lo olvidemos, todas las ritualidades inherentes a una formación coral en el seno de la representación teatral, no es ajeno a la pólis histórica por su propia capacidad performativa de las prácticas corales, ni a la pólis trágica escenificada por ser parte de la misma estirpe argiva, ${ }^{22}$ protegido por su condición de suplicante ante los altares de los dioses, en un espacio que simula ser tierra consagrada según la trama de Suplicantes y que, al mismo tiempo, efectivamente lo está en relación con el culto del dios Dioniso.

Este rol focalizador de Pelasgo parece seguir la siguiente trayectoria: primero, indica la realización de los rituales de suplicación conforme a las pautas griegas (241-243, 333-334, 346-347, 354-355); luego, reconoce la existencia de un origen común entre las Danaides y los argivos (325-326, 356); por último, aun cuando no resulta claro si las bodas pretendidas por los Egiptíadas son ilícitas en Egipto (336, 387-391; cf. 37), se inclina por la aceptación de las doncellas en Argos sobre la base del poder de Zeus como protector de las suplicantes, aunque habiendo aclarado que se puede derramar sangre de varones a causa de mujeres (474-479). Este proceso de identificación conducido por Pelasgo aglutina a los personajes, el coro y el grupo amplio en un conjunto identitario, aunque heteróclito por la diversidad de sus partes: las Danaides, Dánao como padre y guía que comparte el mismo destino, el propio Pelasgo que hace suya la causa de las suplicantes, los argivos de la guardia armada y, finalmente, el pueblo y el conjunto de la pólis de Argos. ${ }^{23}$ Esto termina expresándose en la forma en que se resuelve la situación a través de la decisión de la asamblea argiva (600-624), ${ }^{24}$ reforzando 
la identidad del conjunto de los personajes que hasta aquí han poblado la escena, así como de las fuerzas que han sido invocadas, las de las divinidades cuyas imágenes son adoradas, con Zeus a la cabeza, y las del grupo amplio del pueblo que involucra a toda la ciudad, al que Pelasgo ha colocado por encima de su poder y al que convoca para que por medio de su voto tome una decisión. ${ }^{25}$

Pero antes de arribar a esta situación, Esquilo destaca la capacidad mediadora de Pelasgo a partir de las palabras que le atribuye, con las que responde al coro a la vez que lo trasciende implicando a la pólis y proyectándose hacia los espectadores: "Yo voy a convocar al pueblo del país, para hacerte propicia a la

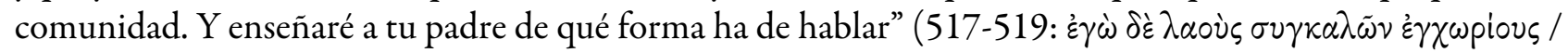

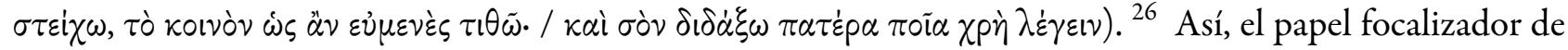
Pelasgo posibilita la identificación entre el coro como grupo y el público, a partir de unos sentimientos que ponen en cadena la unidad de los personajes individuales junto al personaje colectivo del coro, la invocación del poder de los dioses y la unanimidad de la comunidad política: el coro, el grupo más amplio, la audiencia.

\section{A MODO DE CONCLUSIÓN: LAS TENSIONES SUBYACENTES BAJO LA UNANIMIDAD}

La decisión de la asamblea revela que la suplicación ha sido adecuada; desde entonces y hasta el final la obra muestra un bloque monolítico para enfrentar al enemigo extranjero. La forma en que los argivos tomaron la decisión pone de relieve la unidad conseguida destacando su carácter unánime, que se exhibirá en el categórico rechazo de Pelasgo, acompañado por los soldados argivos, ante la pretensión del heraldo de llevarse a las Danaides por la fuerza (940-965). Si en boca de Pelasgo la identidad compartida y el destino

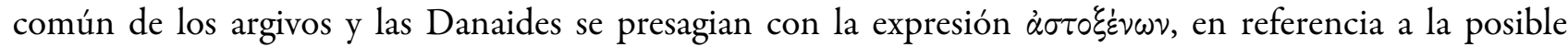
aceptación de estas últimas en la ciudad, en el relato de Dánao sobre la resolución adoptada, que remite a palabras pronunciadas por el líder argivo, la identidad y la ventura colectivas vuelven a invocarse a partir de términos similares asociados: si se desatase la ira de Zeus Hikésios la ciudad se vería afectada por una doble

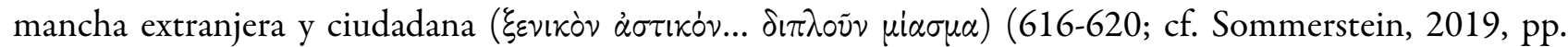
263-264). En virtud de esta ciudad unida (942: $\dot{\varepsilon} \kappa \pi \dot{\partial} \lambda \varepsilon \omega \varsigma$ $\mu i \alpha)$ que se representa en la segunda parte de la obra, la división aparece entonces como la guerra exterior que se avecina con los "nuevos" otros, los Egiptíadas, en la medida en que las Danaides son consideradas residentes legales de la ciudad. El involucramiento ya no es solo de Pelasgo con las Danaides y Dánao, sino que abarca a todo el cuerpo político y la ciudad en su conjunto que las ha incluido como metecos. ${ }^{27}$

Para concluir, el matrimonio, ${ }^{28}$ una de las dimensiones institucionales de la pólis que por mediación del oîkos apuntala su reproducción, permanece en la ambigüedad. ${ }^{29}$ Existe aquí un elemento inherente a la tensión dramática que en el actual estado de cosas no es posible resolver; como primera pieza de la trilogía, o incluso como segunda, las cuestiones que se anuncian en el final de Suplicantes deben quedar necesariamente abiertas, incluso ambigua y contradictoriamente abiertas (cf. 980-1073). La huida de las bodas con unos varones se ha precisado en relación con los hijos de Egipto. ¿Siguen siendo estas bodas las que sirven de referencia en los cantos finales, o se incluye en estos a todo tipo de matrimonio? Puesto que no es evidente si las Danaides rechazan solo las bodas con los Egiptíadas o la institución matrimonial en sí misma, teniendo como horizonte permanecer solteras y vírgenes, cabe argumentar que la indeterminación en torno a este problema tal vez generase interferencias para un involucramiento pleno de la audiencia con el coro. Pero, en este punto, es preciso reiterar que la expresión de los sentimientos de los espectadores por parte del coro puede moverse dentro de un arco de posibilidades que van desde una actitud refractaria a una identitaria. Que Pelasgo opere como focalizador produciendo la convergencia del coro, el grupo amplio y el público no significa que desaparezcan las tensiones, y la audiencia, involucrada a partir de la operatoria detallada, puede haber permanecido en el graderío albergando sentimientos encontrados con respecto a ese grupo extraño pero emparentado. 


\section{Referencias bibliográficAs}

Arnott, P. D. (1989). Public and Performance in the Greek Theatre. London: Routledge.

Bakewell, G. W. (2013). Aeschylus's Suppliant Women: The Tragedy of Immigration. Madison: University of Wisconsin Press.

Bednarowski, K. P. (2011). When the Exodos is not the End: The Closing Song of Aeschylus' Suppliants. Greek, Roman, and Byzantine Studies, 51, 552-578. https://grbs.library.duke.edu/article/view/13011

Budelmann, F. (2000). The Language of Sophocles: Communality, Communication and Involvement. Cambridge: University Press.

Burian, P. (2007). Pelasgus and Politics in Aeschylus' Danaid Trilogy [1974]. En M. Lloyd (Ed.), Oxford Readings in Classical Studies: Aeschylus (pp. 199-210). Oxford: University Press.

Carter, D. M. (2004). Was Attic Tragedy Democratic? Polis, 21(1-2), 1-25. https://doi.org/10.1163/20512996-90 000058

Carter, D. M. (2007). The Politics of Greek Tragedy. Exeter: Bristol Phoenix Press.

Carter, D. M. (2010). The Demos in Greek Tragedy. Cambridge Classical Journal, 56, 47-94. https://doi.org/10.101 $7 / S 1750270500000282$

Carter, D. M. (2013). Reported Assembly Scenes in Greek Tragedy. ICS, 38, pp. 23-63. https://doi.org/10.5406/ill iclasstud.38.0023

Csapo, E. (y Goette, H. R.) (2007). The Men Who Built the Theatres: Theatropolai, Theatronai, and Arkbitektones (An Archaeological Appendix). En P. Wilson (Ed.), The Greek Theatre and Festivals: Documentary Studies (pp. 87-121). Oxford: University Press.

Duchemin, J. (1968). L’áyóv dans la tragédie grecque [1945]. 2a ed. Paris: Les Belles Lettres.

Fernández Deagustini, M. P. (2015). Suplicantes de Esquilo. Una interpretación. La Plata: Universidad Nacional de La Plata. http://sedici.unlp.edu.ar/handle/10915/51947

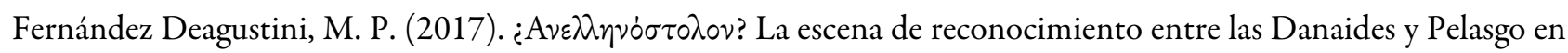
Suplicantes de Esquilo, 234-325. Nova Tellus, 35(2), 45-59. https://doi.org/10.19130/iifl.nt.2017.35.2.767

Fernández Deagustini, M. P. (2018). Deber hacer, poder hacer: los dilemas de Pelasgo en Suplicantes de Esquilo. Habis, 49, 25-42. https://doi.org/10.12795/Habis.2018.i49.02

Ferrari, F. (1974). Il dilemma de Pelasgo. ASNP, s. III, .(2), 375-385.

Foley, H. (2003). Choral Identity in Greek Tragedy. CPh, 98(1), 1-30. https://doi.org/10.1086/378725

Gagné, R. y Hopman, M. G. (2013). Introduction: The Chorus in the Middle. En R. Gagné y M. G. Hopman (Ed.), Choral Mediations in Greek Tragedy (pp. 1-34). Cambridge: University Press.

Gallego, J. (2003). La democracia en tiempos de tragedia. Asamblea ateniense y subjetividad trágica. Buenos Aires: Miño y Dávila.

Gallego, J. (2010). 'Siempre es la pesadilla': las reformas de Efialtes y el derrotero de la democracia radical ateniense. En C. Fornis, J. Gallego, P. López Barja y M. Valdés (Ed.), Dialéctica histórica y compromiso social. Homenaje a Domingo Plácido (t. I, pp. 85-102). Zaragoza: Pórtico.

Gallego, J. (2018). De la volonté tragique à l'action politique: la décision subjective dans la démocratie athénienne. En S. Georgoudi y F. de Polignac (Ed.), Relire Vernant (pp. 227-247). Paris: Les Belles Lettres.

Garvie, A. F. (2006). Aeschylus'Supplices: Play and Trilogy [1969]. 2a ed. Exeter: Bristol Phoenix Press.

Goldhill, S. (1996). Collectivity and Otherness - The Authority of the Tragic Chorus: Response to Gould. En M. S. Silk (Ed.), Tragedy and the Tragic: Greek Theatre and Beyond (pp. 244-256). Oxford: Clarendon Press.

Goldhill, S. (2013). The Greek Chorus: Our German Eyes. En J. Billings, F. Budelmann y F. Macintosh (Ed.), Choruses, Ancient and Modern (pp. 35-51). Oxford: University Press.

Gould, J. (1996). Tragedy and Collective Experience. En M. S. Silk (Ed.), Tragedy and the Tragic: Greek Theatre and Beyond (pp. 217-243). Oxford: Clarendon Press. 
Griffith, M. (1995). Brilliant Dynasts: Power and Politics in the Oresteia. ClAnt, 14(1), 62-129. https://doi.org/10 $.2307 / 25000143$

Güthenke, C. (2013). The Middle Voice: German Classical Scholarship and the Greek Tragic Chorus. En J. Billings, F. Budelmann y F. Macintosh (Ed.), Choruses, Ancient and Modern (pp. 53-66). Oxford: University Press.

Hawthorne, K. (2009). The Chorus as Rhetorical Audience: A Sophoklean Agōn Pattern. AJPh, 130(1), 25-46. http s://www.jstor.org/stable/20616166

Henrichs, A. (1994/95). 'Why Should I Dance?': Choral Self-Referentiality in Greek Tragedy. Arion, s. III, .(1), 56-111. https://www.jstor.org/stable/20163565

Hose, M. (2006). Vaticinium post eventum and the Position of the Supplices in the Danaid Trilogy. En D. Cairns y V. Liapis (Ed.), Dionysalexandros: Essays on Aeschylus and His Fellow Tragedians in Honour of Alexander F. Garvie (pp. 91-98). Swansea: Classical Press of Wales.

Kavoulaki, A. (2011). Choral Self-Awareness: On the Introductory Anapaests of Aeschylus' Supplices. En L. Athanassaki y E. Bowie (Ed.), Archaic and Classical Choral Song: Performance, Politics and Dissemination (pp. 365-390). Berlin: de Gruyter.

Kennedy, R. F. (2014). Immigrant Women in Athens: Gender, Ethnicity, and Citizenship in the Classical City. New York: Routledge.

Kyriakou, P. (2011). The Past in Aeschylus and Sophocles. Berlin: de Gruyter.

Lanza, D. (1977). Il tiranno e il suo pubblico. Torino: Einaudi.

Longo, O. (1990). The Theater of the Polis [1978]. En J. J. Winkler y F. I. Zeitlin (Ed.), Nothing to Do with Dionysos? Athenian Drama in Its Social Context (pp. 12-19). Trad. J. J. Winkler. Princeton: University Press.

McCall, M. (1976). The Secondary Choruses in Aeschylus' Supplices. California Studies in Classical Antiquity, 9, 117-131. https://doi.org/10.2307/25010703

Mastronarde, D. (2010). The Art of Euripides: Dramatic Technique and Social Context. Cambridge: University Press.

Mazon, P. (Ed.). (1920). Eschyle, I: Les Suppliantes. Les Perses. Les Sept contre Thèbes. Prométhée enchainé. Paris: Les Belles Lettres.

Miralles, C. (1992). La refondation athénienne de la condition héroïque. Pallas, 38, 69-78. https://doi.org/10.3406 /palla.1992.1235

Mitchell-Boyask, R. (2008). P. Wilson (Ed.), The Greek Theatre and Festivals: Documentary Studies, Oxford, 2007. BMCRev, 2008.05.24. Recuperado en línea: 17/04/2020. https://bmcr.brynmawr.edu/2008/2008.05.24

Murnaghan, S. (2005). Women in Groups: Aeschylus's Suppliants and the Female Choruses of Greek Tragedy. En V. Pedrick y S. M. Oberhelman (Ed.), The Soul of Tragedy: Essays on Athenian Drama (pp. 183-198). Chicago: University Press.

Murnaghan, S. (2011). Choroi Achoroi: The Athenian Politics of Tragic Choral Identity. En D. M. Carter (Ed.), Why Athens? A Reappraisal of Tragic Politics (pp. 245-267). Oxford: University Press.

Nagy, G. (1994/95). Transformations of Choral Lyric Traditions in the Context of Athenian State Theatre. Arion, s. III, .(1), 41-55. https://www.jstor.org/stable/20163564

Naiden, F. S. (2006). Ancient Supplication. Oxford: University Press.

Page, D. L. (Ed.). (1972). Aeschyli septem quae supersunt tragoedias. Oxford: University Press.

Paiaro, D. (2012). Defendiendo la libertad del dêmos. Control popular y ostracismo en la democracia ateniense. AHAMM, 44, 33-62.

Papadopoulou, T. (2011). Aeschylus: Suppliants. London: Bristol Classical Press.

Pattoni, M. P. (2017). Democratic Paideia in Aeschylus' Suppliants. Polis, 34(2), 251-272. https://doi.org/10.1163 /20512996-12340126

Perea Morales, B. (Trad.). (1986). Esquilo. Tragedias. Intr. M. Fernández-Galiana. Madrid: Gredos.

Podlecki, A. J. (1986). Polis and Monarch in Early Attic Tragedy. En J. P. Euben (Ed.), Greek Tragedy and Political Theory (pp. 76-100). Berkeley: University of California Press. 
Rhodes, P. J. (2003). Nothing to Do with Democracy: Athenian Drama and the Polis. JHS, 123, 104-119. https:// doi.org/10.2307/3246262

Roselli, D. K. (2011). Theater of the People: Spectators and Society in Ancient Athens. Austin: University of Texas Press.

Rösler, W. (2007). The End of the 'Hiketides' and Aischylos' Danaid Trilogy [1993]. En M. Lloyd (Ed.), Oxford Readings in Classical Studies: Aeschylus (pp. 174-198). Trad. M. Lloyd. Oxford: University Press.

Sandin, P. (2005). Aeschylus'Supplices: Introduction and Commentary on vv. 1-523. Lund: Symmachus.

Sansone, D. (2016). The Size of the Tragic Chorus. Phoenix, 70(3-4), 233-254. https://doi.org/10.7834/phoenix.7 $0.3-4.0233$

Schlegel, A.W.von (1815). A Course of Lectures on Dramatic Art and Literature [1809-1811] (Vol. 1-2). Trad. J. Black. London: Baldwin, Cradock \& Joy.

Scullion, S. (2002). Tragic Dates. CQ, 52(1), 81-101. https://doi.org/10.1093/cq/52.1.81

Seaford, R. (1984/85). L'ultima canzone corale delle Supplici di Eschilo. Dioniso, 55, 221-229.

Sicherl, M. (1986). Die Tragik der Danaiden. $M H, 43(2), 81-110$.

Silk, M. S. (1998a). 'Das Urproblem der Tragödie': Notions of the Chorus in the Nineteenth Century. En P. Riemer y B. Zimmermann (Ed.), Der Chor im antiken und modernen Drama (pp. 195-226). Stuttgart: J.B. Metzler.

Silk, M. S. (1998b). Style, Voice and Authority in the Choruses of Greek Drama. En P. Riemer y B. Zimmermann (Ed.), Der Chor im antiken und modernen Drama (pp. 1-26). Stuttgart: J.B. Metzler.

Smyth, H. W. (Ed.). (1922). Aeschylus, I: Suppliant Maidens. Persians. Prometheus. Sept against Thebes. London: W. Heinemann.

Sommerstein, A. H. (1995). The Beginning and the End of Aeschylus' Danaid Trilogy. En B. Zimmermann (Ed.), Griechisch-römische Komödie und Tragödie (pp. 111-134). Stuttgart: M und P.

Sommerstein, A. H. (1997). Theatre Audience, the Demos, and the Suppliants of Aeschylus. En C. Pelling (Ed.), Greek Tragedy and the Historian (pp. 63-79). Oxford: Clarendon Press.

Sommerstein, A. H. (Ed.). (2019). Aeschylus: Suppliants. Cambridge: University Press.

Swift, L. A. (2010). The Hidden Chorus: Echoes of Genre in Tragic Lyric. Oxford: University Press.

Taplin, O. (1977). The Stagecraft of Aeschylus: The Dramatic Use of Exits and Entrances in Greek Tragedy. Oxford: Clarendon Press.

Tarkow, T. A. (1970). The Dilemma of Pelasgus and the Nautical Imagery of Aeschylus' Suppliants. C\&M, 31, 1-13.

Vernant, J.-P. y Vidal-Naquet, P. (1972). Mythe et tragédie en Grèce ancienne I. Paris: Maspero.

Vernant, J.-P. y Vidal-Naquet, P. (1986). Mythe et tragédie en Grèce ancienne II. Paris: La Découverte.

West, M. L. (Ed.). (1992). Aeschyli: Supplices. Stuttgart: Teubner.

West, M. L. (2006). King and Demos in Aeschylus. En D. Cairns y V. Liapis (Ed.), Dionysalexandros: Essays on Aeschylus and his Fellow Tragedians in Honour of Alexander F. Garvie (pp.31-40). Swansea: Classical Press of Wales.

Wiles, D. (1997). Tragedy in Athens: Performance Space and Theatrical Meaning. Cambridge: University Press.

Wilson, P. (2000). The Athenian Institution of Khoregia: The Chorus, the City and the Stage, Cambridge: University Press.

Winnington-Ingram, R. P. (1983). Studies in Aeschylus. Cambridge: University Press.

Zeitlin, F. I. (1996). Playing the Other: Gender and Society in Classical Greek Literature. Chicago: University Press.

\section{Notas}

1 Uso la edición de Sommerstein (2019), cotejada con las de Mazon (1920), Smyth (1922) y West (1992), cuando deja opciones abiertas, y la traducción de Perea Morales (1986), modificada en tanto que se basa en la edición de Page (1972). Retorno aquí a temas analizados en Gallego (2003, pp. 400-408, 489-529); en la medida en que he estudiado allí la figura del héroe trágico, el problema de la decisión subjetiva y los elementos políticos presentes en Suplicantes, no abordo aquí 
estas cuestiones ni vuelvo a examinar la bibliografía citada en esas páginas, excepto cuando la argumentación desarrollada así lo exige.

2 Si bien hay trabajos previos, con su estudio, originalmente publicado en 1969, Garvie (2006, pp. ix-xii, xv, 1-87) sentó las bases de los análisis actuales de la tragedia y la nueva datación; también Sommerstein (1997, pp. 74-79; 2019, pp. 40-44); Scullion (2002); Sandin (2005, pp. 1-4).

3 Contra Taplin (1977, pp. 206-209); Scullion (2002, p. 95). Ver Fernández Deagustini (2015, pp. 11-27).

4 Las posturas que se agrupan presentan matices y desarrollos críticos que no podemos abordar aquí: cf. Arnott (1989, p. 34); Henrichs (1994/95, pp. 59, 67-70, 76); Nagy (1994/95, p. 52); Wiles (1997, pp. 123-124). Hawthorne (2009, pp. 27-28) y Mastronarde (2010, p. 101) se inscriben en esta perspectiva.

5 En una línea similar desarrolla su perspectiva Foley (2003) acerca del rol, la identidad y la autoridad del coro dentro de las obras, habida cuenta de su usual configuración marginal como entidad colectiva y, por ende, de no ser representativo de la audiencia teatral. La autora destaca la figura del corego en el proceso institucionalizado de selección de los festivales dionisíacos, apoyándose en el análisis fundamental de Wilson (2000). La crítica más frontal al punto de vista propiciado por Vernant probablemente sea la de Carter (2010, pp. 59-73; cf. 2007, pp. 79-83), al que califica como "la falacia colectiva”. En la base de su argumento se encuentra su convicción de que la tragedia ática no era esencialmente democrática ni en cuanto al contexto de los festivales, cuya audiencia no era solo ateniense, ni en cuanto a las temáticas desarrolladas por las obras, que en términos políticos apuntan a cuestiones inherentes a la pólis en general y no solo a la Atenas democrática; cf. Rhodes (2003); Carter (2004; 2007, pp. 1-8, 64-89). Ver el balance sobre las posturas de Vernant y Gould que llevan a cabo Gagné y Hopman (2013, pp. 25-28).

6 Cf. Silk (1998b, pp. 24-25); Hawthorne (2009, pp. 25-26 n. 3), sobre marginalidad y autoridad del coro.

7 Sobre la cuestión de la conciencia trágica, cf. Vernant y Vidal-Naquet (1972, p. 36). Según Goldhill, la visión de Vernant resignifica la fórmula del "espectador ideal", propuesta por Schlegel (1815, t. I, pp. 77-79), lo cual se percibe en sus concepciones sobre la polivalencia del lenguaje trágico y lo trágico en sí mismo. Para análisis de la noción de "espectador ideal", Silk (1998a); Goldhill (2013); Güthenke (2013).

8 Aun si la audiencia teatral pudo incluir en Atenas a extranjeros y a no ciudadanos, un aspecto elocuente de los festivales consistía en mostrar el poder de la ciudad a estos espectadores eventualmente presentes (tributo de los aliados, desfile de huérfanos de guerra, etc.). En función de esto se postula que el público se componía fundamental y mayoritariamente de ciudadanos varones adultos. Un punto complementario es la ponderación de esta audiencia según su estatus social y su capacidad de costearse la entrada al teatro, antes de la existencia del theorikón en el siglo IV. Se ha indicado que en el siglo V los pobres pudieron ocupar espacios "no oficiales" sin gradas, pagando menos de dos óbolos, o nada; MitchellBoyask (2008): "I still suspect one could argue compellingly for around 10,000, with many more on the slope above the theater", comentando las estimaciones de Csapo (2007, pp. 96-100) sobre la cantidad de espectadores sentados en el teatro de Dioniso en el siglo V (entre 4.000 y 7.000); cf. Roselli (2011, pp. 72-75).

9 Gould (1996, pp. 218-219) lo bautiza con el nombre de "modelo Vernant" honoris causa, pero toma la idea del coro como representativo del cuerpo ciudadano del artículo ya citado de Longo. Carter (2010, pp. 63-64) cita textualmente el pasaje de Vernant y reitera la frase en la que se habla del coro como expresión de los sentimientos del público para destacar que muchos han ido más allá de Vernant al afirmar que el coro representa a la comunidad, reenviando a Longo; pero no discute el significado de esos sentimientos; lo mismo ocurre con Murnaghan (2011, pp. 246-247), que también cita a Longo. Gagné y Hopman (2013, pp. 25-26) destacan asimismo la influencia de Longo como comentarista de Vernant e indican que el "modelo Vernant" se deriva más de las simplificaciones de los seguidores que del propio Vernant.

10 En este punto cobra relevancia tanto lo que la tragedia nos permite obtener como lo que la trilogía en su conjunto pudo haber presentado sobre la escena, aportando una información y no otra. Pero, de todas las ideas sugeridas, ninguna irradia una certeza más allá de toda duda razonable y nos constriñe a evaluar las posibilidades solo a partir de la pieza disponible. Desde inicios del siglo XIX se ha propuesto que la secuencia de la trilogía debió ser: Suplicantes, Egiptíadas y Danaides (Schlegel, 1815, t. I, p. 108), solo en parte confirmada por el papiro conteniendo la didascalia que ha hecho cambiar la datación de la pieza (Garvie, 2006, pp. viii, xviii-xix, 1-28, 185-186; Sandin, 2005, pp. 9-12). Algunos autores han propuesto revisar la secuencia de la trilogía, a partir de una exégesis de Suplicantes, v. 37 y un escolio, en relación con un oráculo que habría recibido Dánao, cuestión que parece haber perdido peso últimamente: Sicherl (1986, pp. 88-94, 98-99); Rösler (2007, pp. 177-184); Sommerstein (1995, pp. 113-121); Sandin (2005, p. 11 n. 30); Hose (2006); Garvie (2006, pp. xvii-xviii); Kyriakou (2011, pp. 65-76). Sommerstein (2019, pp. 10-20) ha aceptado las críticas de Garvie, desechando el oráculo y el escolio como fuente para el mismo, pero refuerza su postura a favor de que Egiptiadas es la primera pieza.

11 Sobre las versiones del mito Danaide, Papadopoulou (2011, pp. 25-38); Sommerstein (2019, pp. 4-10).

12 Origen bárbaro, color de piel, vestimenta, legalidad o no de las bodas con los primos, dichos ambiguos sobre el matrimonio y la figura masculina, no seguir los canales usuales para establecerse, etc. 
13 Antepasados comunes con los argivos, suplicación conforme a las pautas griegas, respeto a la autoridad del padre, pedido de asilo amparado por las divinidades, derecho a la residencia sustentado en una alianza a partir de la hospitalidad y un origen cívico compartido, etc.

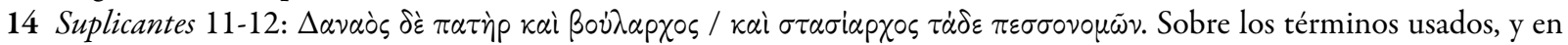
particular $\sigma \tau \alpha \sigma i \alpha$ pxos (junto a $\sigma \tau \dot{\lambda} \lambda \circ \nu$, ad 2), Sandin (2005, pp. 45-46 ad 12); Kavoulaki (2011, pp. 371-382); Fernández Deagustini (2015, pp. 51-53 y nn. 67-72); Sommerstein (2019, pp. 97, 116 ad 73: ả $\phi i \lambda \circ v \tau \tilde{\alpha} \sigma \delta \varepsilon \phi v \gamma \tilde{\alpha} \varsigma)$. Sobre el liderazgo

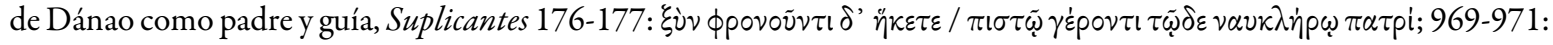

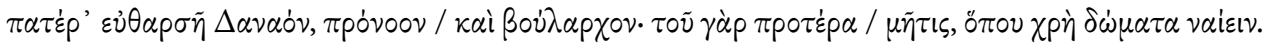

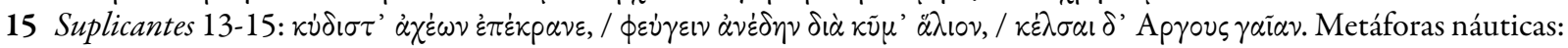
vv. 408-409, 438-441, 468-471 (cf. vv. 258-259); cf. Tarkow (1970).

16 Murnaghan (2005, pp. 190-191) apela a figuras arcaicas en las que coros de mujeres aparecen bajo la dirección de un khoregós, varón adulto mayor, como sería el caso de Dánao en Suplicantes, apoyándose en análisis de la tragedia previos a la nueva datación. Kavoulaki (2011, pp. 368, 374 y n. 34, 377) ve en Dánao más como tutor y director del coro que como padre y protector y lo asocia con la función del corego, y cita a Wilson en cuanto a la posibilidad de que corego y corifeo coincidan, lo cual pudo ocurrir eventualmente. Pero parece claro que, como indica Wilson (2000, pp. 130-136), existe una separación entre actores y coreutas: por una parte, la distinción entre esferas asignadas en la performance; por otra parte, en caso de participar como líder del coro, el corego estaba integrado al coro y solo se distinguía del grupo en los momentos en que tomaba la palabra como representante del conjunto o líder artístico. Por la economía de la trama, la función de Dánao, como personaje individual, está ligada a la de las Danaides, como personaje colectivo, en tanto que ejerce como padre y guía respecto de sus hijas.

17 Suplicantes 176-179 (prudencia siguiendo consejos paternos); 188-233 (formas de suplicar a los dioses y de hablar a los argivos, mostrando respeto y subordinación); 710-712, 724-725, 773 (mesura ante el peligro y devoción a los dioses, a pesar del temor por el arribo de los Egiptíadas); 980-1017 (plegarias a los argivos, prudencia recordando consejos paternos y modestia ante los deseos varoniles).

18 Cf. Sommerstein (2019, pp. 193-194). La expresión $\dot{\alpha} \sigma \tau 0 \xi \dot{\varepsilon} \nu \omega \nu$ articula una serie de enunciados: en boca de Dánao, él

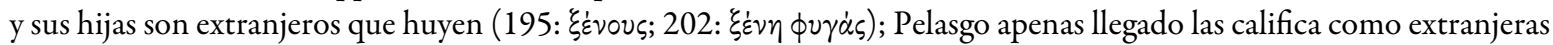
(277: $\xi \dot{\xi} v \alpha \iota)$ recriminándoles que han venido sin representante (239: $\dot{\alpha} \pi \rho \dot{o} \xi \varepsilon v o l)$. Una vez que Pelasgo ha resignificado

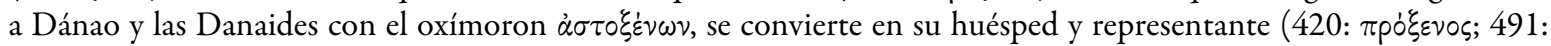

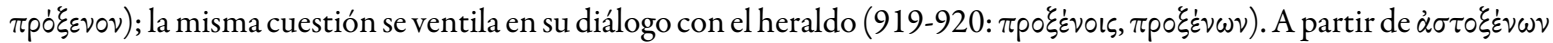
cobran sentido otros enunciados: si las Danaides van a recibir un lugar en la ciudad, el asunto implica a todos los ciudadanos, dice Pelasgo (369: $\dot{\alpha} \sigma \tau o i ́ s ~ \delta \dot{\varepsilon} \pi \tilde{\alpha} \sigma$ ); Dánao consiente en que hasta que esto no ocurra debe ser guiado para conducirse seguro por la ciudad (495: $\dot{\alpha} \sigma \phi \dot{\alpha} \lambda \varepsilon 1 \alpha \delta^{\prime} \dot{\eta} \delta \iota^{\prime} \alpha \dot{\alpha} \sigma \varepsilon \omega \varsigma$; cf. 500-501). Una fórmula que despliega el oxímoron

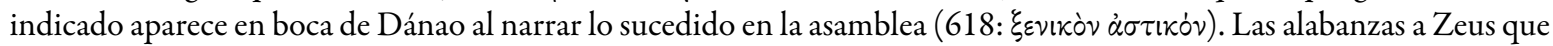

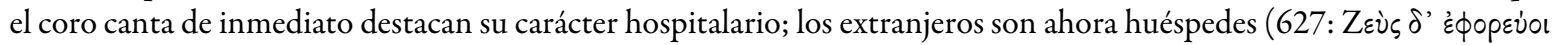

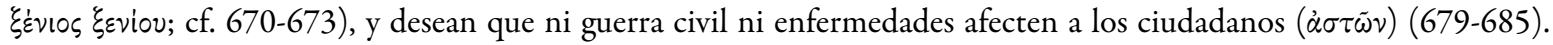
Cuando el heraldo se presenta, Pelasgo lo ve como el extraño absoluto que no sabe comportarse como extranjero (917:

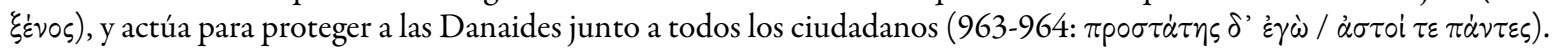

19 La coyuntura política en la que se representa Suplicantes, los años 470-460, se considera generalmente un momento de profundización de la democracia en Atenas, donde desde fines del siglo VI se aplicaba el ostracismo como modo de control sobre los líderes; cf. Gallego (2003, pp. 65-94; 2010); Paiaro (2012).

20 Algunos análisis desestiman que Argos sea democrática porque el poder no ha sido transferido totalmente al pueblo: Burian (2007, pp. 200-204); Podlecki (1986, pp. 82-85); West (2006, pp. 35-37). Mi postura (Gallego, 2003, pp. 506-513) es similar a la de Garvie (2006, p. 150; cf. p. xvi).

21 Sobre la figura de Pelasgo, ver Burian (2007), que analiza su dilema en el plano intrínseco de la obra, y la reformulación que plantea Fernández Deagustini (2015, pp. 160-177; 2018). Cf. Tarkow (1970); Ferrari (1974); Papadopoulou (2011, pp. 66-69); Gallego (2018, pp. 226-229).

22 Como señala Fernández Deagustini (2015, pp. 162-167; 2017), en el reconocimiento las Danaides pasan de ser una

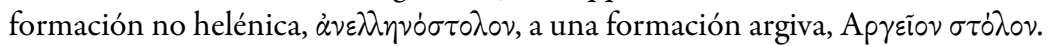

23 La implicación del grupo amplio fuera de escena es un recurso evidente en Suplicantes, de principio a fin, empezando por las referencias a la ciudad ( $\pi \dot{\partial} \lambda \mathrm{l}$ ). En boca de las Danaides (D.), Pelasgo (P.) y Dánao se registran, en las diferentes facetas que la configuran como grupo, veintiséis menciones a la ciudad: y voto (7, D.; 942, P.); y territorio (23, D.); y líder (248, 905 , D.); y oratoria (273, P.); y altares/divinidades (345, 670, 1020, D.); y guerra (357-358, P.); y cuerpo político (366, P.; 618-619, Dánao; 660, D.); y rey (370, D.); y ley (388, P.); y totalidad del grupo humano (401, 410, 913, P.; 1023, D.); y guerra civil $(680$, D.); y poder del pueblo $(699$, D.); y gobierno $(775,1010$, Dánao) y murallas (centro urbano) (955, P.). Este conjunto de apelaciones a la ciudad se complementa y potencia con el uso de diferentes vocablos que remiten a la comunidad de ciudadanos en su conjunto como la que políticamente decide, tales como el pueblo: $\lambda \alpha \dot{\varsigma} \varsigma$ (367, 400,

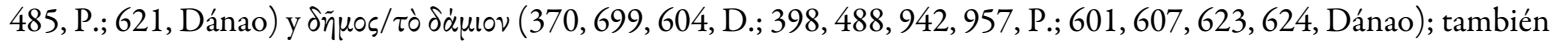


los ciudadanos, siempre en plural: $\dot{\alpha} \sigma \tau \dot{\omega} \varsigma$ (369, 964: P., $\dot{\alpha} . \pi \tilde{\alpha} \sigma \iota$ y $\dot{\alpha} . \pi \dot{\alpha} \nu \tau \varepsilon \varsigma ;$ 684, D.), y $\pi \dot{\alpha} \nu \tau \varepsilon \varsigma \pi 0 \lambda \tilde{i} \tau \iota$ (484, P.). A estos usos se suman otros que denotan igualmente la idea de grupo amplio: la humanidad (90, D.: $\mu \varepsilon p \dot{\pi} \pi \varepsilon \sigma \sigma \iota \lambda \alpha \sigma i ̂ \varsigma)$; residentes legales (356, P.: $\dot{\alpha} \sigma \tau 0 \xi \dot{\xi} \nu \omega \nu)$.

24 Ver Sommerstein (2019, pp. 256-264). Cf. Gallego (2003, pp. 506-513); Carter (2013, pp. 29-34).

25 La capacidad de decisión política, mediante el voto, es invocada a lo largo de toda la obra, incluyendo al lugar de origen de las Danaides en esta práctica: el voto, $\psi \tilde{\eta} \phi \circ \varsigma(7,640,644,739,943,965)$, los decretos, $\psi \eta \phi i \sigma \mu \alpha \tau \alpha(601)$, o la acción de levantar la mano para votar, $\chi \varepsilon i p(604,607,621)$.

26 Adopto ad 518 la lectura $\sigma \tau \varepsilon i \chi \omega$, sugerida por Smyth (1922) y West (1992), entre otros. Sommerstein (2019, ad 518, y p. 233) aclara que $\pi \dot{\varepsilon} \tau \omega$ en el manuscrito es un sinsentido, pero deja la cuestión abierta. Otras lecturas consultadas: Mazon, 1920: $\pi \alpha \tau \tilde{\omega}$; Page, 1972: $\sigma \pi \varepsilon \dot{\sigma} \sigma \omega$.

27 Pelasgo es garante de esta protección como prostátes; 963-964: $\pi p \circ \sigma \tau \dot{\alpha} \tau \eta \varsigma \delta$ ' $\dot{\varepsilon} \gamma \dot{\omega}$ / $\dot{\alpha} \sigma \tau o \dot{\tau} \tau \varepsilon \pi \dot{\alpha} \nu \tau \varepsilon \varsigma$; Dánao y las Danaides

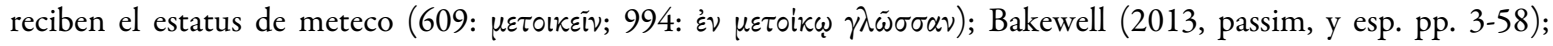
Papadopoulou (2011, pp. 68-71); Kennedy (2014, pp. 26-67).

28 Se trata de un asunto debatido: ¿las Danaides huyen de las bodas con los Egiptíadas o de cualquier boda, rechazando al género masculino y renegando de los roles aceptados? Zeitlin (1996, pp. 123-171) propone que, al rechazar las bodas con sus primos, las Danaides se rebelan contra la propia institución del matrimonio; para Bednarowski (2011), en cambio, el rechazo es solo hacia las bodas con los Egiptíadas.

29 La respuesta a esto está atravesada por la cuestión del desdoblamiento del coro en el canto final (vv. 1018-1073). Se ha planteado que al coro de Danaides se suma otro de sirvientas ( $\delta \mu \omega i \delta \varepsilon \varsigma, \theta \varepsilon p \alpha \pi \circ v \tau i \delta \alpha)$, al menos desde el v. 977, que cantarían los versos que señalan la importancia del matrimonio, dando a entender así un posible rechazo general de esta institución; Mazon (1920); Smyth (1922); Winnington-Ingram (1983, p. 60 y n. 20). Otra visión indica que el coro de Danaides se divide en dos, por lo que no habría rechazo de las bodas en general; McCall (1976); Bednarowski (2011). La tercera postura considera que se suma un coro de soldados argivos, a cargo de los versos atribuidos a las sirvientas, de manera que también en esta visión se podría pensar en un rechazo general del matrimonio; Garvie (2006, p. xvi; cf. pp. 193-195); Taplin (1977, pp. 230-238); Seaford (1984/85); Rösler (2007, p. 188); Papadopoulou (2011, pp. 15, 81-83, 92); Sommerstein (2019, pp. 36-37, 308-309, 350-352, 363-364), quien además propone que un coro de Egiptíadas alterna con las Danaides (Suplicantes 825-865) y luego habla el heraldo. 